\title{
CATALYTIC TRANSFORMATION OF SEED OIL DERIVATIVES VIA OLEFIN METATHESIS
}

\author{
Scott, S.L. ${ }^{*}$ \\ Department of Chemical Engineering, University of California, \\ Santa Barbara CA 93106-5080 USA \\ Received: October 10, 2006 \\ Accepted: May 15, 2007
}

\begin{abstract}
SUMMARY
Unsaturated fatty acid esters derived from seed oils undergo metathesis at the $\mathrm{C}=\mathrm{C}$ bond to give new internal and terminal olefins of interest in chemical manufacturing. The key to realizing this industrial opportunity is the ability to deploy catalysts that tolerate functional groups and remain reactive towards internal olefins even at high conversions. Recent developments in catalyst and reactor design are bringing these targets closer to commercial reality.
\end{abstract}

Key words: unsaturated fatty acid esters, renewable feedstocks, seed oils

\section{INTRODUCTION}

Recent dramatic increases in the price of crude oil have presented the world's chemical industry with an opportunity and an obligation to investigate the use of renewable rather than fossil-based feedstocks for the manufacture of chemical intermediates and materials. Fatty acid esters derived from seed oils are an appealing alternative source of chemicals, since their chemical structures are closely related to those of the hydrocarbons in crude oil. The use of seed oil-based feedstocks in environmentally benign and sustainable chemical manufacturing has the potential to reduce net $\mathrm{CO}_{2}$ emissions and produce non-toxic materials that are also biodegradable. Single component or high purity feedstocks are preferred, because chemical separations are generally energy- and capital-intensive. Thus high oleic sunflower oil, with an oleate content after transesterification approaching $90 \%$, is particularly well-suited as a renewable chemical feedstock.

Traditionally, almost all reactions of seed oils were conducted at the ester functionality, with the exception of hydrogenation which eliminates the $\mathrm{C}=\mathrm{C}$ double bond (Baumann et al., 1988). In recent years, many other reactions at this site have been explored (Biermann et al., 2000). Olefin metathesis, in which substituents of the double bond are exchanged, is considered a desirable technology because it is

* Corresponding author: email: sscott@engineering.ucsb.edu 
highly atom-efficient. The reaction leads to the formation of new olefinic compositions (Figure 1).<smiles>[R]C([R])=C([R])[R]</smiles><smiles>[R]C([R])=C([R])[R]</smiles><smiles>[R]C([R])=C([R])[R]</smiles><smiles>[R3]C=C[R]</smiles><smiles>[R]C([R3])=C([R])C</smiles>

Figure 1: Redistribution of olefinic substituents via the metathesis reaction

The nature of the products obtained depends on the type of olefinic substrate: acyclic monounsaturated substrates give acyclic olefins (simple metathesis), $\alpha, \omega$ unsaturated dienes and strained cyclic olefins give polymers (acyclic diene metathesis polymerization, ADMET, and ring-opening metathesis polymerization, ROMP), some dienes give unstrained rings by extrusion of ethylene (ring-closing metathesis, $\mathrm{RCM}$ ) and cycloolefins may give larger cycloolefins (ring-expanding metathesis). For all these reactions, the universal Chauvin mechanism involves [2+2] cycloaddition of the olefin substrate to a metal carbene catalyst, followed by cycloreversion of the metallacyclobutene intermediate (Figure 2).

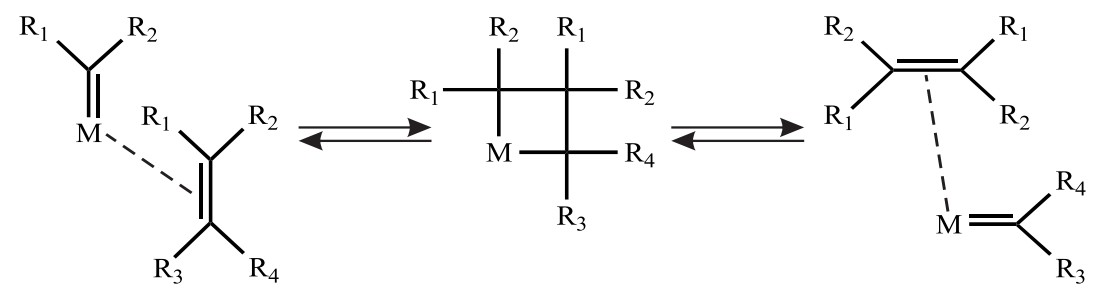

Figure 2: Mechanism of catalytic olefin metathesis via alternation of the metal carbene and metallacyclobutane propagating intermediates

In principle, olefin metathesis is highly selective. However, side-reactions such as olefin isomerization are common, and deactivation has been a major problem with existing catalyst technology.

\section{Self-metathesis of fatty acid methyl esters (FAMEs)}

Self-metathesis, or homometathesis, requires no reagent other than the olefin itself. Thus homometathesis of the FAME methyl oleate yields an unsaturated diester, dimethyl-9-octadecene-1,18-dioate, and an internal olefin, 9-octadecene (Figure 3).

One potential application for homometathesis is the reformulation of biodiesel, in order to enhance its viscosity and lubricity without compromising stability or biodegradability (Holser et al., 2006). A second application is the production of pol- 
ymers. Long chain dicarboxylic acid esters were shown to undergo condensation polymerization at $150-200^{\circ} \mathrm{C}$ with diols such as ethylene glycol, 1,4-butanediol and 1,4-bis(hydroxymethyl)cyclohexane, in the presence of a Lewis acid catalyst, $\mathrm{Ti}\left(\mathrm{O}^{\mathrm{t}} \mathrm{Bu}\right)_{4}$ (Warwel et al., 2001). Unlike their petroleum-based aromatic analogues, the resulting aliphatic polyesters are biodegradable. Finally, olefin metathesis is a key reaction in the catalytic formation of macrocycles. Homometathesis of ethyl oleate to give diethyl-9-octadecene-1,18-dioate was followed by cyclization via the Dieckmann condensation, ester hydrolysis and decarboxylation to 9-cycloheptadecen-1-one (Tsjui and Hashiguchi, 1981). By an alternate route, cyclization by RCM of oleon (pentatriaconta-9,26-dien-18-one), the product of Claisen condensation of methyl oleate, gives the same macrocycle (Plugge and Mol, 1991). Although neither synthetic route is stereoselective, the cis-isomer of the macrocyclic ketone is the valuable musk ingredient civetone.

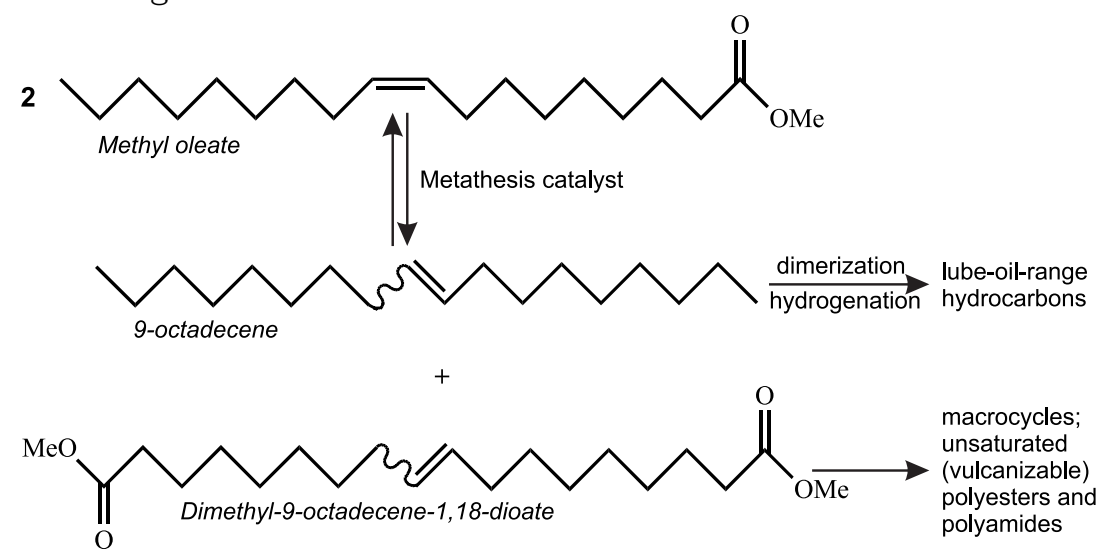

Figure 3: Homometathesis of methyl oleate

\section{Metathesis catalysts for FAMEs}

The presence of an ester group in the olefinic substrate makes it essential to use a catalyst that tolerates functional groups and is active at moderate reaction temperatures in the liquid phase. The former requirement rules out high-valent, single-component homogeneous catalysts based on Mo and W, while the latter rules out unpromoted heterogeneous catalysts based on supported metal oxides of these metals. The first report of methyl oleate self-metathesis involved a two-component homogeneous catalyst, $\mathrm{WCl}_{6} / \mathrm{SnMe}_{4}$ (Van Dam et al., 1972), in which the active metal (W) was likely reduced from its maximum oxidation state by the alkyltin promoter. The same catalyst system was also reported to catalyze the homometathesis of glyceryl trioleate, yielding octadec-9-ene and dicarboxylic acid glyceryl esters. Subsequently, the diene methyl linolate and the triene methyl linolenate were shown to react over the same homogeneous catalyst to give cyclohexa-1,4-diene by $\mathrm{RCM}$, as well as acyclic alkenes and unsaturated mono- and dicarboxylic esters 
(Verkuijlen and Boelhouwer, 1974). A heterogeneous catalyst for these reactions, $\mathrm{SnMe}_{4}$-promoted $\mathrm{Re}_{2} \mathrm{O}_{7} / \mathrm{Al}_{2} \mathrm{O}_{3}$, was discovered shortly afterwards (Verkuijlen et al., 1977). It was proposed that the role of the alkyltin promoter is reduction of high-valent Re(VII) (Xiaoding et al., 1985).

Catalysts based on late transition metals (Groups 8-10 in the Periodic Table) are more stable in low and intermediate oxidation states, and they tend to be more tolerant of substrate functionality. In one of the earliest reports, a 4:1 mixture of $\mathrm{AgO}_{2} \mathrm{CCF}_{3}$ and $[\mathrm{Ir}(\mathrm{coe}) \mathrm{Cl}]_{2}$ (coe is cyclooctene) catalyzed the selective homometathesis of 10 equiv. methyl oleate to octadec-9-ene and the unsaturated diester, accompanied by small amounts of products derived from isomerization (France et al., 1994). The $\mathrm{AgO}_{2} \mathrm{CCF}_{3}$ was suggested to abstract chloride and oxidize $\mathrm{Ir}(\mathrm{I})$ to $\operatorname{Ir}(\mathrm{III})$. More recent studies of homogeneous FAME metathesis reactions have focused on single-component, isolable Ru-based catalysts, known as Grubbs' catalysts (Figure 4). The first generation of these catalysts, which bear two bulky trialkylphosphine ligands (1), have low thermal stability at $50^{\circ} \mathrm{C}$ and low reactivity towards internal olefins. Catalyst stability is also generally poor at low loadings, limiting opportunities for commercial applications in which high turnovers are required. Thermal stability is much improved in the second-generation catalysts $\mathbf{2}$ and $\mathbf{3}$, in which one phosphine ligand is replaced by an N-heterocyclic carbene ligand such as 1,3bis(2,4,6-trimethylphenyl)imidazol-2-ylidene (IMes). The second generation catalysts also show higher activity, especially for functionalized and internal olefins (Weskamp et al., 1998), although often at the expense of selectivity. Thus catalyst 3 showed a productive turnover number for methyl oleate homometathesis of 440,000 at $55^{\circ} \mathrm{C}$, compared to 2,500 for catalyst 1a (Dinger and Mol, 2002). New first-generation Grubbs' catalyst with phosphanabicyclononane (Phoban) ligands show improved thermal stability while retaining very high selectivity for the selfmetathesis of methyl oleate (Forman et al., 2004).

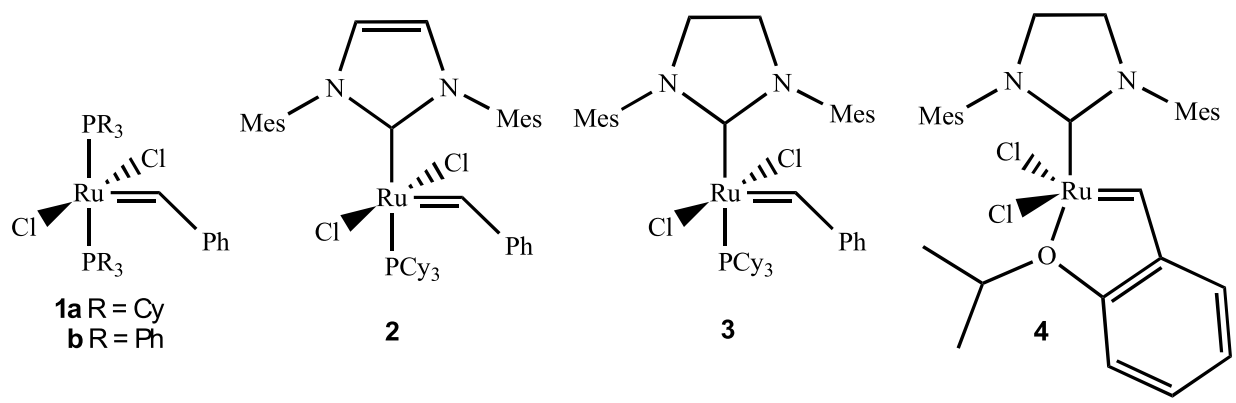

Figure 4: Typical Grubbs' first generation (1a,b) and second generation (2-4) catalysts.

A major drawback in the use of homogeneous metathesis catalysts for largescale processes is the high cost of catalyst separation and recovery. Incomplete catalyst removal leads to undesirable product isomerization during product purification; furthermore, the ability to use low conversion with recycle to surpass 
equilibrium-limitations to conversion is difficult with a homogeneous catalyst. Catalyst decomposition products lead to loss of selectivity due to side-reactions at high turnovers, particularly during recycle (Dinger and Mol, 2002). Immobilizing homogeneous ruthenium catalysts onto a solid support, such as functionalized polystyrene-divinylbenzene, can extend their lifetimes but is accompanied by considerable loss of activity (Nguyen and Grubbs, 1995) and/or pronounced leaching (Nieczypor et al., 2001). A supported organometallic catalyst obtained by grafting $\operatorname{Re}\left(\equiv \mathrm{C}^{\mathrm{t}} \mathrm{Bu}\right)$ $\left(=\mathrm{CH}^{\mathrm{t}} \mathrm{Bu}\right)\left(\mathrm{CH}_{2}{ }^{\mathrm{t}} \mathrm{Bu}\right)_{2}$ onto silica gave 900 turnovers in the homometathesis of methyl oleate (Chabanas et al., 2003), however, like the homogeneous catalysts, it is intrinsically non-regenerable and therefore far below the threshold for commercial viability. Since the products of seed oil homometathesis are not volatile enough to be removed by vaporization, one possible solution to the separation problem is the use of size-selective membranes. A reactor equipped with a polyimide nanofiltration membrane to reject the homogeneous catalyst and its decomposition products has been proposed for continuous recycle operation (Burdett et al., 2006).

Although preferred for large-scale industrial processes, heterogeneous metathesis catalysts show much lower effective turnover numbers for FAMEs than most homogeneous catalysts, and particularly in comparison to the newest Grubbs' catalysts. For example, one of the best heterogeneous formulations is $\operatorname{Re}_{2} \mathrm{O}_{7}$ supported on borated silica-alumina. The addition of a promoter, typically an organotin compound such as $\mathrm{SnBu}_{4}$, is required in order to prevent catalyst deactivation by polar functional groups. The promoted catalyst gave 198 turnovers in methyl oleate selfmetathesis (Buffon et al., 2002). While heterogeneous metathesis catalysts have the advantage of being readily reactivated by calcination when the promoter is absent, the buildup of $\mathrm{SnO}_{2}$ after repeated additions of $\mathrm{SnR}_{4}$ interferes with active site regeneration (Spronk and Mol, 1991). The search for a tin-free catalyst is also driven by the toxicity of organotin promoters. A hypothesis that alkyltin compounds cause in situ generation of organorhenium(VII) trioxides was supported by the finding that a tin-free catalyst active in methyl oleate self-metathesis can be prepared by deposition of $\mathrm{MeReO}_{3}$ onto silica-alumina (Herrmann et al., 1991). Recently, $\mathrm{MeReO}_{3}$ formation was predicted computationally and observed spectroscopically in a $\mathrm{SnMe}_{4}$-promoted perrhenate catalyst (Moses et al., 2006). The mechanism of activation of $\mathrm{MeReO}_{3}$ by the support involves Lewis acid-base interactions between the oxo ligands and distorted four-coordinate aluminum sites, as well as between $\operatorname{Re}(\mathrm{VII})$ and support oxygen atoms (Moses et al., 2006). These interactions may reduce the barrier for tautomerization of the methyl ligand to a carbene capable of initiating olefin metathesis, although reduction of $\operatorname{Re}(\mathrm{VII})$ has not been excluded.

\section{FAME cross-metathesis}

Cross-metathesis is performed in the presence of a second olefin, typically an acyclic olefin with symmetrical double-bond substituents. It can result in chain lengthening or chain shortening, depending on the choice of olefin. Cross-metathe- 
sis of methyl oleate with a light olefin leads to the more valuable detergent-range FAMEs. The ideal cross-metathesis reaction from an economic standpoint is ethenolysis, leading to 1-decene and methyl-9-decenoate. In principle, this reaction is not equilibrium-limited: it can be driven to completion simply by the use of a high pressure of ethylene (Figure 5). Terminally-unsaturated methyl esters are precursors for polymers including polyesters, polyethers and polyamides, and they can be copolymerized with $\alpha$-olefins to yield functionalized polyolefins. The $\alpha$-olefins can be used as detergent precursors and as comonomers for polyolefins. Cross-metathesis with a cyclic olefin $\mathrm{C}_{n} \mathrm{H}_{2 n}$ is also possible, and can be used to extend the carbon chain by $n$ units. For example, the reaction of methyl oleate with cyclododecene gave the unsaturated ester $\mathrm{CH}_{3}\left(\mathrm{CH}_{2}\right)_{7} \mathrm{CH}=\mathrm{CH}\left(\mathrm{CH}_{2}\right)_{10} \mathrm{CH}=\mathrm{CH}\left(\mathrm{CH}_{2}\right)_{7} \mathrm{CO}_{2} \mathrm{CH}_{3}$ which, after catalytic reduction, yielded the plant growth hormone triacontanol $\mathrm{CH}_{3}\left(\mathrm{CH}_{2}\right)_{28} \mathrm{CH}_{2} \mathrm{OH}$ (Villemin, 1983).

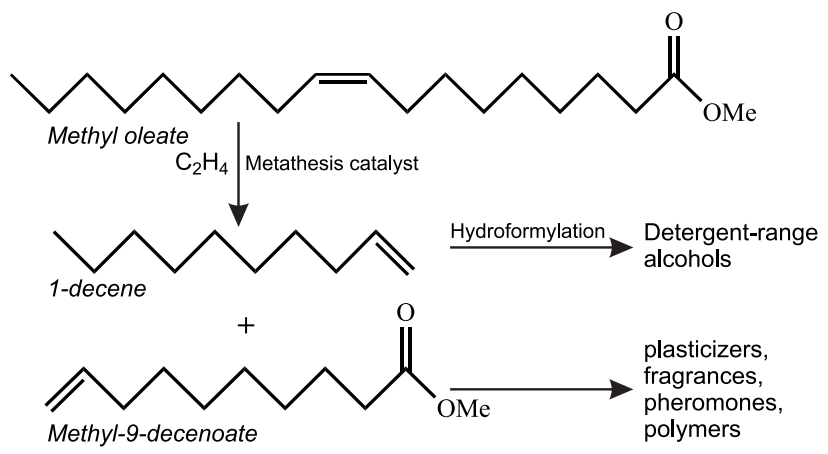

Figure 5: Ethenolysis of methyl oleate

One problem limiting selectivity in metathesis is competing olefin isomerization (migration of the $\mathrm{C}=\mathrm{C}$ bond), particularly at high turnovers and with the secondgeneration Grubbs' catalysts (Janse van Rensburg et al., 2004). Isomerization is catalyzed by the metathesis catalyst or one of its decomposition products. In the case of the Grubbs' catalysts, the culprit was shown to be a ruthenium hydride (Hong et al., 2004). Isomerization was suppressed by the addition of 1,4-benzoquinone, which was reduced to hydroquinone by the metal hydride (Hong et al., 2005). Addition of a phenol (500 equiv. per $\mathrm{Ru}$ ) enhanced catalyst lifetime ten-fold in a first-generation Grubbs' catalyst, and increased selectivity in a second-generation Grubbs' catalyst, allowing higher substrate/catalyst ratios in cross-metathesis and conferring resistance to degradation by feedstock impurities such as ketones, alcohols, aldehydes, alkynes, dienes and peroxides (Forman et al., 2005).

Heterogeneous metathesis catalysts tend to be highly selective in FAME crossmetathesis. Warwel et al. ( 2001), converted 600 equiv. FAMEs from high oleic sunflower oil to 1-decene and methyl-9-decenoate ( $>80 \%$ recovered yield) by reaction with 50 bar ethylene at $20^{\circ} \mathrm{C}$ for $2 \mathrm{~h}$ using the heterogeneous catalyst $\mathrm{SnBu}_{4}$-promoted $\mathrm{Re}_{2} \mathrm{O}_{7}$ supported on borated silica-alumina (Warwel et al., 2001). Copolym- 
erization of the resulting terminally-unsaturated methyl ester with 2.5 bar ethylene at $25^{\circ} \mathrm{C}$ using a Pd diimine catalyst gave highly branched, functionalized polyethylene with potential application as a compatibilizer for polyolefins and polar polymers (Warwel et al., 2001). Transesterification of the unsaturated methyl ester with a diol gives an $\alpha, \omega$-alkylene dialkenoate, which undergoes ADMET polymerization over $\mathrm{SnBu}_{4}$-promoted $\mathrm{Re}_{2} \mathrm{O}_{7}$ /borated silica-alumina. Reaction of methyl oleate with excess 1-hexene suppresses undesired homometathesis to give, selectively, 3dodecene and methyl-9-dodecenoate (Mol, 2002). Cis-trans isomerization of methyl oleate was not a problem in batch reactor tests. However, buildup of the trans isomer, which undergoes metathesis more slowly, could become an issue in a continuous reactor with catalyst recycle (Burdett et al., 2004).

Commercial viability for methyl oleate cross-metathesis is predicated on obtaining a minimum of 50,000 turnovers (Burdett et al., 2004). The limited number of turnovers reported in many catalyst systems for ethenolysis of methyl oleate (Warwel et al., 2001; Dinger and Mol, 2002) has been attributed to the production of terminal olefins, which engage in degenerate olefin metathesis (Burdett et al., 2004). This problem may be circumvented by performing cross-metathesis with a symmetrical internal olefin, such as 2-butene. Using second-generation Grubbs' catalysts, effective turnover numbers of up to 440,000 were found (Patel et al., 2005). However, the catalyst efficiency was strongly dependent on the purity of both the methyl oleate and the 2-butene. The presence of polyunsaturates, or of 1,3-butadiene, leads to catalyst deactivation, likely via the formation of vinyl alkylidenes (Schwab et al., 1996). In addition, the instability of the ruthenium methylidene intermediate in the ethenolysis pathway restricts reactions to low temperatures and, consequently, low rates. This limitation has been overcome to some extent with new Phoban-based Grubbs' catalysts, which show higher methylidene stability (Forman et al., 2004).

Recently, the ethenolysis problem was tackled by simple substitution of the solvent system. Immobilization of a homogeneous catalyst in the liquid phase was achieved using an ionic liquid as solvent (Lacombe et al., 2006). Under these conditions, the terminal $\alpha$-olefins are only slightly miscible, and therefore separate spontaneously. This prevents the catalyst from being tied up in unproductive degenerate metathesis reactions, since it remains in the ionic liquid. High conversions can therefore be achieved, and the catalyst can be recycled and reused. However, the ecotoxicity of ionic liquids may be a concern (Wells and Coombe, 2006). Thus the search for effective, regenerable heterogeneous metathesis catalysts for converting FAMEs to other usable chemical feedstocks continues.

\section{ACKNOWLEDGEMENT}

Our olefin metathesis research is supported by the U.S. Department of Energy, Basic Energy Sciences, Catalysis Science Grant No. DE-FGO2O3ER15467. 


\section{REFERENCES}

Baumann, H., Bühler, M., Fochem, H., Hirsinger, F., Zoebelein, H. and Falbe. J., 1988. Angew. Chem. Int. Ed. 27: 41-62.

Biermann, U., Friedt, W., Lang, S., Lühs, W., Machmüller, G., Metzger, J.O., Rüsch Gen. Klaas, M., Schäfer, H.J. and Schneider, M.P., 2000. New syntheses with oils and fats as renewable raw materials for the chemical industry. Angew. Chem. Int. Ed. 39: 2207-2224.

Buffon, R., Marochio, I.J., Rodella, C.B. and Mol. J.C., 2002. Germanium and silicon compounds as promoters for $\mathrm{Re}_{2} \mathrm{O}_{7} / \mathrm{SiO}_{2}-\mathrm{Al}_{2} \mathrm{O}_{3}$ metathesis catalysts. J. Mol. Catal. 190: 171176.

Burdett, K.A., Collins, R.M., Maughon, B.R. and Tulchinsky, M.L., 2006. Membrane separation of a metathesis reaction mixture. WO/2006/047105.

Burdett, K.A., Harris, L.D., Margl, P., Maughon, B.R., Mokhtar-Zadeh, T., Saucier, P.C. and Wasserman, E.P., 2004. Renewable monomer feedstocks via olefin metathesis: Fundamental mechanistic studies of methyl oleate ethenolysis with the first-generation Grubbs catalyst. Organometallics 23: 2027-2047.

Chabanas, M., Copéret, C. and Basset, J.-M. 2003. Re-based heterogeneous catalysts for olefin metathesis prepared by surface organometallic chemistry: Reactivity and selectivity. Chem. Eur. J. 9: 971-975.

Dinger, M.B., and Mol, J.C., 2002. High turnover numbers with ruthenium-based metathesis catalysts. Adv. Synth. Catal. 344: 671-677.

Forman, G.S., McConnell, A.E., Hanton, M.J., Slawin, A.M.Z., Tooze, R.P., Janse van Rensburg, W., Meyer, W.H., Dwyer, C., Kirk, M.M. and Serfontein, D.W., 2004. A stable ruthenium catalyst for productive olefin metathesis. Organometallics 23: 4824-4827.

Forman, G.S., McConnell, A.E., Tooze, R.P., Janse van Rensburg, W., Meyer, W.H., Kirk, M.M., Dwyer, C.L. and Serfontein, D.W., 2005. A convenient system for improving the efficiency of first-generation ruthenium olefin metathesis catalysts. Organometallics 24: 45284542.

France, M.B., Feldman, J. and Grubbs, R.H., 1994. An iridium-based catalyst system for metathesis/isomerization of acyclic olefins, including methyl-oleate. J. Chem. Soc., Chem. Commun. pp. 1307-1308.

Herrmann, W.A., Wagner, W., Flessner, U.W., Volkhardt, U. and Komber, H., 1991. Methyltrioxorhenium as catalyst for olefin metathesis. Angew. Chem. Int. Ed. 30: 1636-1638.

Holser, R.A., Doll, K.M. and Erhan, S.Z., 2006. Metathesis of methyl soyate with ruthenium catalysts. Fuel 85: 393-395.

Hong, S.H., Day, M.W. and Grubbs, R.H., 2004. Decomposition of a key intermediate in ruthenium-catalyzed olefin metathesis reactions. J. Am. Chem. Soc. 126: 7414-7415.

Hong, S.H., Sanders, D.P., Lee, C.W. and Grubbs, R.H., 2005. Prevention of undesirable isomerization during olefin metathesis. J. Am. Chem. Soc. 127: 17160-17161.

Janse van Rensburg, W., Steynberg. P.J., Meyer. W.H., Kirk, M.M. and Forman. G.S., 2004. DFT prediction and experimental observation of substrate-induced catalyst decomposition in ruthenium-catalyzed olefin metathesis. J. Am. Chem. Soc. 126: 14332-14333.

Lacombe, S., Revel, R., Briot, P., Llido, E., Euzen, P. and Bobin, C., 2006. Process for coproducing olefins and esters by ethenolysis of unsaturated fats in non-aqueous ionic liquids. US 2006/0079704.

Mol, J.C., 2002. Application of olefin metathesis in oleochemistry: An example of green chemistry. Green Chem. pp. 5-13.

Moses, A.W., Leifeste, H.D., Ramsahye, N.A., Eckert, J. and Scott, S.L., (2006). Supported Re catalysts for the metathesis of functionalized olefins. Catal. Org. React. in press.

Moses, A.W., Ramsahye, N.A., Raab, C., Leifeste, H.D., Chattopadhyay, S., Chmelka, B.F., Eckert, J. and Scott, S.L., 2006. Methyltrioxorhenium interactions with Lewis acid sites of an amorphous silica-alumina. Organometallics 25: 2157-2165.

Nguyen, S.T. and Grubbs, R.H., 1995. The syntheses and activities of polystyrene-supported olefin metathesis catalysts based on $\mathrm{Cl}_{2}\left(\mathrm{PR}_{3}\right)_{2} \mathrm{Ru}=\mathrm{CH}-\mathrm{CH}=\mathrm{CPh}_{2}$. J. Organomet. Chem. 497: 195-200

Nieczypor, P., Buchowicz, W., Meester, W.J.N., Rutjes, F.P.J.T. and Mol, J.C., 2001. Synthesis and application of a new polystyrene-supported ruthenium carbene catalyst for alkene metathesis. Tetrahedron Lett. 42: 7103-7105. 
Patel, J., Mujcinovic, J., Jackson, W.R., Robinson, A.J., Serelis, A.K., Such, C., 2006. High conversion and productive catalyst turnovers in cross-metathesis reactions of natural oils with 2-butene. Green Chem. pp. 450-454.

Plugge, M.F.C. and Mol, J.C., 1991. A new synthesis of civetone. Synlett: 507-508.

Schwab, P., Grubbs, R.H. and Ziller, J.W., 1996. Synthesis and applications of $\mathrm{RuCl}_{2}\left(=\mathrm{CHR}^{\prime}\right)\left(\mathrm{PR}_{3}\right)_{2}$ : The influence of the alkylidene moiety on metathesis activity. J. Am. Chem. Soc. 118: 100-110.

Spronk, R. and Mol, J.C., 1991. Regeneration of rhenium-based catalysts for the metathesis of propene. Appl. Catal. 76: 143-152.

Tsjui, J. and Hashiguchi, S., 1981. Metathesis reactions of unsaturated esters catalyzed by homogeneous tungsten complexes. Synthesis of civetone and macrolides. J. Organomet. Chem. 218: 69-80.

Van Dam, P.B., Mittelmeijer, M.C. and Boelhouwer, C., 1972. Metathesis of unsaturated fatty acid esters by a homogeneous tungsten hexachloride-tetramethyltin catalyst. J. Chem. Soc., Chem. Commun. pp. 1221-1222.

Verkuijlen, E. and Boelhouwer, C., 1974. Formation of cyclohexa-1,4-diene by metathesis of linoleic and linolenic esters. J. Chem. Soc., Chem. Commun. pp. 793-794.

Verkuijlen, E., Kapteijn, F., Mol, J.C. and Boelhouwer, C., 1977. Heterogeneous metathesis of unsaturated fatty acid esters. J. Chem. Soc., Chem. Commum. pp. 198-199.

Villemin, D. 1983. Synthése du triacontanol par métathése fonctionalisée. Tetrahedron Lett. 24: 2855-2866.

Warwel, S., Brüse, F., Demes, C., Kunz, M. and Rüsch Gen. Klaas, M., 2001. Polymers and surfactants on the basis of renewable resources. Chemosphere 43: 39-48.

Wells, A.S. and Coombe, V.T., 2006. On the freshwater ecotoxicity and biodegradation properties of some common ionic liquids. Org. Process Res. Dev. 10: 794-798.

Weskamp, T., Schattenmann, W.C., Spiegler, M. and Herrmann, W.A., 1998. A novel class of ruthenium catalysts for olefin metathesis. Angew. Chem. Int. Ed. 37: 2490-2493.

Xiaoding, X., Andreini, A. and Mol, J.C., 1985. The role of $\mathrm{SnR}_{4}$ compounds in the metathesis of alkenes catalyzed by $\mathrm{Re}_{2} \mathrm{O}_{7} / \gamma_{-} \mathrm{Al}_{2} \mathrm{O}_{3}$ : An ESR study. J. Mol. Catal. 28: 133-140.

\title{
TRANSFORMACIÓN CATALÍTICA DE LOS DERIVADOS DEL ACEITE A TRAVÉS DE METÁTESIS OLEFÍNICA
}

\author{
RESUMEN
}

Los estros de los ácidos grasos no saturados obtenidos del aceite vegetal, pasan por metátesis del vínculo $\mathrm{C}=\mathrm{C}$, con lo cual se forman nuevas olefinas internas y terminales, interesantes para la industria química. El factor clave en la realización de esta posibilidad industrial, es la posibilidad de sintetizarse los catalizadores correspondientes que puedan tolerar la presencia de diferentes grupos funcionales, guardando la reactividad hacia el vínculo olefínico interno, hasta en la ocasión de múltiple conversión. Los recientes perfeccionamientos de catalizadores y reactores, acercan estas metas a la realidad comercial.

\section{TRANSFORMATION CATALYTIQUE DES DÉRIVÉS DE L'HUILE PAR LA MÉTATHÈSE D'OLÉFINES}

RÉSUMÉ

Les esters d'acides gras non saturés obtenus de l'huile végétale passent par métathèse au lien $\mathrm{C}=\mathrm{C}$ et de nouvelles oléfines internes et terminales intéressantes pour l'industrie chimique sont formées. Le facteur clef dans la réalisation de cette perspective industrielle est la capacité de synthétiser les catalyseurs qui seraient en mesure de tolérer la présence de différents groupes fonctionnels tout en gardant la réactivité envers le lien d'oléfine interne, et 
même à haute conversion. De récents progrès dans les catalyseurs et les réacteurs rapprochent ces buts de la réalité commerciale. 